
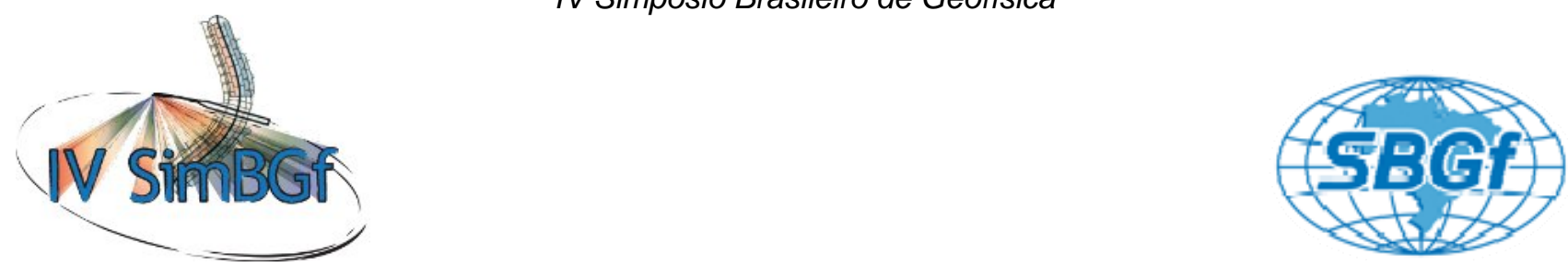

\title{
Aplicação do método da Polarização Induzida (IP) no monitoramento de vazamento de combustível em sedimentos: estudo em escala laboratorial.
}

\author{
Leonardo Zani Castello - UNESP, Antonio C.O. Braga - UNESP, César A. Moreira - UNESP.
}

Copyright 2010, SBGf - Sociedade Brasileira de Geofísica

Este texto foi preparado para a apresentação no IV Simpósio Brasileiro de Geofísica Brasília, 14 a 17 de novembro de 2010. Seu conteúdo foi revisado pelo Comite Técnico do IV SimBGf, mas não necessariamente representa a opinião da SBGf ou de seus associados. É proibida a reprodução total ou parcial deste material para propósitos comerciais sem prévia autorização da SBGf

\section{Resumo}

Estudos ambientais envolvendo investigação e mapeamento do meio geológico por meio de métodos geoelétricos apresentam resultados satisfatórios que sugerem eficácia no emprego desses métodos em situações que apresentem alterações dos componentes do subsolo devido à presença de combustíveis, como o etanol. Aplicando o método geofísico da polarização induzida (IP), por meio da técnica de perfilagem elétrica, foi monitorada a variação temporal do parâmetro físico cargabilidade em sedimentos arenosos alterados devido à contaminação controlada de etanol, contidos em um tanque de monitoramento. O presente trabalho objetiva avaliar o comportamento do etanol num experimento que simula condições hidrogeológicas reais, bem como caracterizar as variações temporais no parâmetro geoelétrico cargabilidade.

\section{Introdução}

Frente ao grande potencial de produção do etanol como combustível para veículos movidos por motores à combustão no Brasil, sobretudo pelo clima favorável e a vasta área disponível para a plantação da cana-deaçúcar, este combustível é amplamente utilizado no transporte e utilização para esses veículos.

Devido ao uso intenso desses combustíveis, existe uma ampla rede de transporte e distribuição, sendo freqüente a ocorrência de acidentes com impacto direto nos solos e águas subterrâneas.

O comportamento de um contaminante em contato com o meio geológico está associado as suas propriedades físico-químicas e as características dos materiais que constituem o terreno (FERREIRA \& ZUQUETTE, 1998).

Diversos trabalhos realizam esse tipo de estudo com o objetivo de avaliar os impactos causados pela contaminação por combustíveis de origem fóssil, como a gasolina e óleo diesel (CASSIDY et al. 2001; BRAGA et al. 2008, LIMA et al. 2005).

Contudo, praticamente inexistem estudos que abordem os efeitos causados pela presença de etanol no meio geológico. Diante desta deficiência de estudos, se torna relevante o desenvolvimento de pesquisas que abordem este tema.

As alterações das propriedades físicas do meio geológico nessas condições são passíveis de detecção pelos métodos geofísicos. Os métodos geoelétricos são especialmente aplicáveis nesses casos devido à ampla gama de variação das propriedades elétricas em áreas contaminadas

O uso combinado de poços de amostragem e métodos geofísicos constitui uma maneira adequada para identificação e o monitoramento de áreas contaminadas.

Esses métodos são utilizados principalmente nas fases de prevenção, para caracterização geológica e identificação de áreas vulneráveis, como terrenos com elevada permeabilidade e nível freático raso. Nas etapas de avaliação preliminar e diagnóstica, a geofísica pode ser aplicada para delimitação 2D e 3D de plumas de contaminação, e determinação das áreas de maior concentração de contaminantes.

Um estudo visando correlações geológico-geoelétrica foi realizado por Draskovits et al. (1990) para os métodos da Eletrorresistividade e Polarização Induzida, por meio das técnicas de campo da sondagem elétrica vertical e perfilagem elétrica. Dentre as considerações feitas pelo autor, vale destacar as seguintes:

- A resposta IP em camadas com misturas de areias e argilas é bem maior que a resposta em camadas argilosas puras.

- Argilas puras apresentam baixa resistividade e baixa polarização.

- Camadas arenosas apresentam alta resistividade e cargabilidade intermediária.

- Camadas siltosas apresentam alta polarização e resistividade intermediária.

Foi utilizado por Moreira \& Braga (2008) o método da polarização induzida em estudo para determinação da área de percolação do material lixiviado oriundo de um aterro de resíduos sólidos domiciliares do tipo vala, localizado município de Cordeirópolis/SP. Segundo os resultados obtidos pela pesquisa, os autores sugerem associação de anomalias de alta cargabilidade nas valas recentemente fechadas do aterro a prováveis acúmulos de minerais férricos nas bases das mesmas, enquanto as valas mais antigas apresentam parâmetros que tendem ao valor do background da área, pressupondo a decomposição natural dos resíduos.

Experimentos geofísicos em escala laboratorial podem resultar dados importantes para a compreensão de casos reais em campo, bem como estabelecer padrões, para o 
caso de materiais ou corpos geológicos e tendências, para o caso de aqüíferos ou águas contaminadas.

\section{Metodologia/ Problema Investigado}

Foi estruturado um ambiente em escala laboratorial no qual foi monitorado o comportamento geoelétrico de sedimentos que foram alterados por uma contaminação induzida e controlada por etanol.

Com o objetivo de estimar a profundidade limite de detecção de modelos condutivos e resistivos em escala laboratorial utilizando o método da eletrorresistividade, Apparao et al (1992 e 1997) efetuaram medidas em um tanque com água onde foram submersos corpos esféricos, cilíndricos e tabulares constituídos de alumínio (metal condutivo) e ebonite (material sintético de elevada resistividade). Os autores atestam que as profundidades de detecção foram maiores para os corpos condutivos, sugerindo algumas limitações do método da eletrorresistividade em áreas essencialmente resistivas.

Estudos geofísicos em escala laboratorial acerca do método da eletrorresistividade foram realizados por Sumner (1976). O autor salienta que o parâmetro resistividade varia de forma linear em função dos potenciais elétricos medidos. Desta forma, é possível a determinação de potenciais de forma indireta, pois o produto das resistividades por um fator de escala resulta em valores de potenciais proporcionais (SUMNER, 1976).

Estudos geofísicos em escala laboratorial foram realizados por Atekwana et al. (2000), para avaliação do comportamento geoelétrico em locais contaminados por combustíveis fósseis. Os autores apontam que em locais onde ocorram alterações químicas significativas do hidrocarboneto, devem ocorrer mudanças na assinatura geoelétrica de resistiva para condutiva. Afirmam ainda que é possível a existência dessa zona condutiva devido à biodegradação do contaminante.

Por meio da aplicação do método da eletrorresistividade em um local contaminado por combustíveis fósseis, Werkema et al. (2003) destacam a presença de grandes quantidades de bactérias degradadoras em áreas com baixos valores de resistividade elétrica. Os autores sugerem a influência da atividade biológica na magnitude do parâmetro físico.

Estudos geofísicos de contaminações de aqüíferos por combustíveis fósseis em escala laboratorial foram realizados por Cassidy, et al. (2001). Os autores sugerem que a biodegradação desses compostos sob condições aeróbicas e anaeróbicas podem ocasionar mudanças consideráveis nas condições biogeoquímicas do aqüífero, com queda drástica de resistividade elétrica.

Um estudo de contaminações rasas em escala laboratorial foi realizado por Taioli et al. (2006). O estudo apresenta um dispositivo elaborado para medidas de resistividade elétrica, composta por uma fonte de corrente alternada e uma ponteira de PVC com eletrodos para medição. Os resultados foram satisfatórios nas faixas de resistividade estudadas e propõe aplicações para o dispositivo, como estudo de contaminações rasas em áreas arenosas.

O estudo de Braga et al. (2008) monitorou a dinâmica de evolução de uma contaminação em escala laboratorial com o objetivo de determinar o comportamento temporal do hidrocarboneto em relação ao parâmetro físico resistividade elétrica. Os resultados sugerem um aumento da resistividade associada aos primeiros períodos pós-contaminação, seguida de uma relativa estabilidade e posterior queda dos valores e tendência de retorno às condições naturais.

Os ensaios geofísicos foram desenvolvidos em um tanque de fibra de vidro, com as seguintes dimensões na parte útil: 2,34 m (comprimento) x 1,34 m (largura) x 0,47 $\mathrm{m}$ (altura), preenchido por areia de granulometria fina a média (Figura 1). Nesse tanque foi simulado vazamento do combustível álcool etílico hidratado.

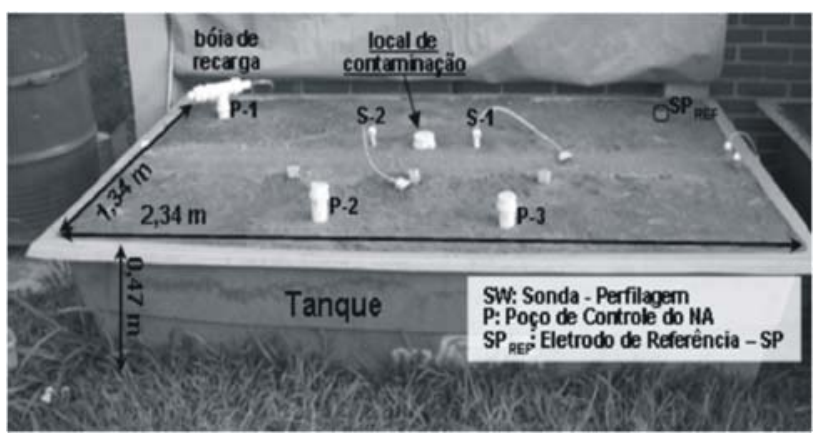

Figura 01 - Local de desenvolvimento da pesquisa.

A utilização de modelos controlados para o estudo de contaminações possibilita o entendimento da dinâmica e do comportamento temporal desses compostos. Fenômenos de degradação, dispersão e diluição produzem alterações das propriedades físicas em solos, rochas e águas subterrâneas.

Foram realizados ensaios geoelétricos de referência no local de estudo, visando caracterizar o comportamento natural da área sem a presença do contaminante. Com isso, foi possível o estabelecimento de comparações nos valores obtidos no background da área em relação aos medidos nos ensaios que analisaram os sedimentos com a presença do etanol, em função do tempo, caracterizando o monitoramento geofísico.

Foi mantido de forma constante um horizonte insaturado e um horizonte saturado, por meio da permanência de um nível freático a uma profundidade média de $10,0 \mathrm{~cm}$. Para o controle da saturação no tanque, foram instalados três poços de controle $(P)$, construídos com tubos de PVC, com 50,0 cm de comprimento e $6,0 \mathrm{~cm}$ de diâmetro.

Pequenos furos na parte inferior permitiram a entrada de água no sistema. Com o objetivo de estabelecer a mínima variação do nível freático, a recarga do sistema foi mantida partir de um sistema de controlado de abastecimento instalado no poço P-1. 


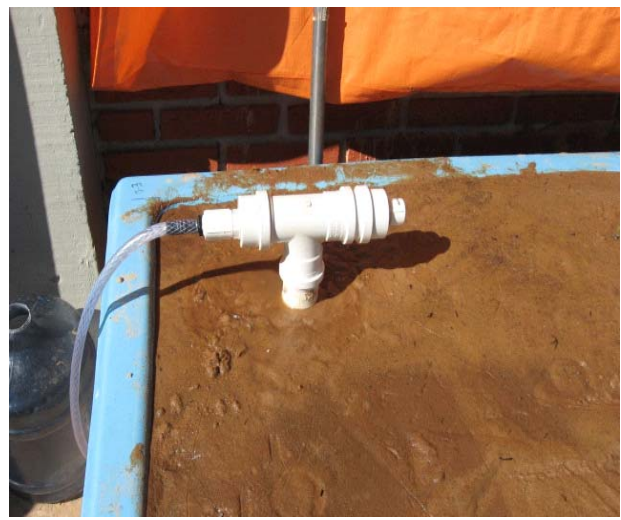

Figura 01 - Bóia de Recarga

A saturação parcial dos sedimentos teve como objetivo simular as condições reais de campo. A característica de miscibilidade do contaminante na água permite monitorar seu comportamento por longos períodos. A eventual contaminação do experimento insaturado resultaria num breve período de monitoramento, devido à elevada volatilidade do contaminante.

A existência de níveis de saturação proporcionou o estabelecimento de padrões nas variações temporais dos parâmetros em relação às águas subterrâneas, e sua influência quando em contato com o contaminante, que é caracterizado como miscível, diferentemente de combustíveis como a gasolina e o óleo diesel.

A montagem do tanque de monitoramento foi realizada com o objetivo de obter um volume máximo de sedimentos. A montagem se iniciou com a deposição dos sedimentos de maneira irregular, posteriormente os sedimentos foram uniformizados e nivelados manualmente.

As leituras do parâmetro cargabilidade foram realizadas por meio de duas sondas (S) instaladas desde a superfície até a base do tanque, na posição vertical (Figura 02).

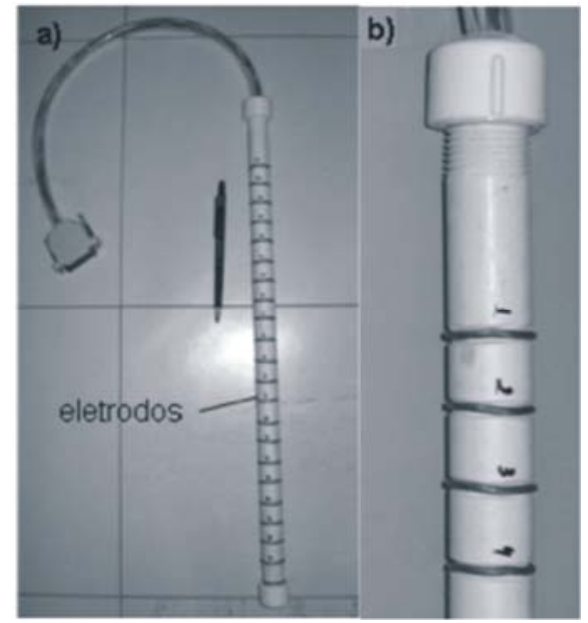

Figura 2 - Sonda utilizada (a) na perfilagem elétrica - (b) detalhe.
O vazamento simulado foi efetivado de forma pontual no centro do tanque, por meio da introdução de 20 litros de álcool combustível.

Foi utilizado o resistivímetro Terrameter SAS 4000, fabricado pela ABEM (Suécia), com resolução de $1 \mu \mathrm{V}$. Este equipamento é calibrado para medidas de resistividade por meio de ciclos periódicos de corrente elétrica alternada e de baixa freqüência, procedimento que permite a filtragem de ruídos do sinal adquirido.

\section{Caracterização do Contaminante}

O etanol $\left(\mathrm{CH}_{3} \mathrm{CH}_{2} \mathrm{OH}\right)$, também chamado álcool etílico, é uma substância obtida da fermentação de açúcares. No Brasil, esta substância é muito utilizada como combustível de motores de explosão, constituindo assim um mercado em ascensão.

O etanol é o mais comum dos álcoois. Os álcoois são compostos que têm grupos hidroxila ligados a átomos de carbono. Podem ser vistos como derivados orgânicos da água, em que um dos hidrogênios foi substituído por um grupo orgânico.

O etanol ou álcool etílico hidratado combustível (AEHC) é um produto resultante da destilação final decorrente do processo de obtenção de açúcar de cana, caracterizado como uma mistura hidroalcoólica com teor alcoólico mínimo de $92,6^{\circ}$ INPM. O produto foi especificado pela ANP por meio da Resolução ANP no 36, de 6/12/2005.

Utilizado principalmente como combustível para veículos e também como produto de limpeza doméstica ou industrial, quando utilizado nas concentrações recomendadas.

São estabelecidas as especificações técnicas do Álcool Etílico Hidratado Combustível (AEHC), comercializados por diversos agentes econômicos no território nacional, como destinado para utilização como combustível para motores de combustão interna com ignição por centelha, enquanto o Álcool Etílico Anidro Combustível (AEAC) é destinado para a mistura com gasolina tipo $A$, para a formulação da gasolina tipo C. (ANP, 2002).

Estudos sobre a importância do etanol na atenuação natural de águas subterrâneas impactadas por gasolina foram realizados por Nunes et al (2007). Foram avaliados os resultados de um experimento de derramamento controlado de gasolina brasileira em água subterrânea durante 6,5 anos. A exaustão do etanol aos 32 meses de monitoramento, e a significativa redução de mais de $90 \%$ da massa máxima dos compostos BTEX (Benzeno, Tolueno, Etilbenzeno e Xileno) dissolvidos no meio aos 79 meses, demonstraram a eficácia da atenuação natural nas contaminações de águas subterrâneas.

Somente após a exaustão do etanol, ocorrida após 32 meses, foi iniciada a redução de massa de BTEX. Os resultados revelam que a biodegradação do etanol permitiu a formação de uma barreira natural que, após a sua completa degradação, acelerou a taxa de biodegradação dos BTEX e impediu o avanço da pluma. 


\section{Resultados}

Os resultados do monitoramento geoelétrico apontam as dinâmicas de variações temporais do parâmetro cargabilidade de sedimentos e águas subterrâneas frente a uma contaminação induzida de etanol. A apresentação dos resultados considera essas variações para os sedimentos contaminados, em comparação aos seus valores naturais obtidos no primeiro ensaio realizado, que diz respeito ao comportamento geoelétrico dos sedimentos saturados e insaturados sem a presença do etanol (background).

A possibilidade de controle sobre os valores dos níveis d'água nos ensaios geoelétricos possibilitou análises dos resultados considerando as variações do parâmetro medido sob a influência da água em nível constante.

Foram estabelecidos resultados em dois estratos geoelétricos na análise das variações temporais: saturado e insaturado.

A determinação dos estratos geoelétricos considera a influência da água nas variações dos parâmetros geoelétricos investigados, portanto adotou-se dois níveis para cada estrato geoelétrico nas análises médias dessas variações. Para o estrato geoelétrico insaturado, adotou-se o nível insaturado 01 (Ni01) e nível insaturado 02 (Ni02), e para o estrato geoelétrico saturado adotouse o nível saturado 01 (Ni01) e o nível saturado 02 (Ni02).

Os resultados das perfilagens elétricas apresentam a variação vertical (investigação em profundidade) do parâmetro cargabilidade obtido no monitoramento geoelétrico.

As escalas dos eixos foram mantidas constantes em todos os ensaios realizados, de maneira que os resultados do parâmetro analisado pode ser comparado em função do tempo de monitoramento, para os quatro níveis adotados.

A curva de cargabilidade referência (ensaio 01) revela valores de $0,7 \mathrm{~ms}$ e $2,0 \mathrm{~ms}$ paras as sondas $\mathrm{SW}-01$ e $\mathrm{SW}-02$, respectivamente para a faixa insaturada dos sedimentos.

Para esse mesmo ensaio, os valores de cargabilidade para os sedimentos saturados apresentaram valores distintos para as duas sondas elétricas, porem esses valores apresentaram as mesmas tendências de variação para a faixa saturada, de valores próximos a $2,0 \mathrm{~ms}$ (Figura 03).

Após 4 horas de contaminação a cargabilidade apresenta pequeno aumento na faixa insaturada, atingindo $3 \mathrm{~ms}$, e constância nos valores relativos à faixa saturada para as duas sondas.

As curvas de cargabilidades obtidas em 12 horas e 52 horas apresentam tendências parecidas de variação para os sedimentos saturados e insaturados.
Após 12 horas os valores são próximos de $4,0 \mathrm{~ms}$ para 0 topo da faixa insaturada dos sedimentos. Com o aumento da profundidade de investigação sofrem variações, atingindo valores próximos à $5 \mathrm{~ms}$ e $3 \mathrm{~ms}$ no NA.

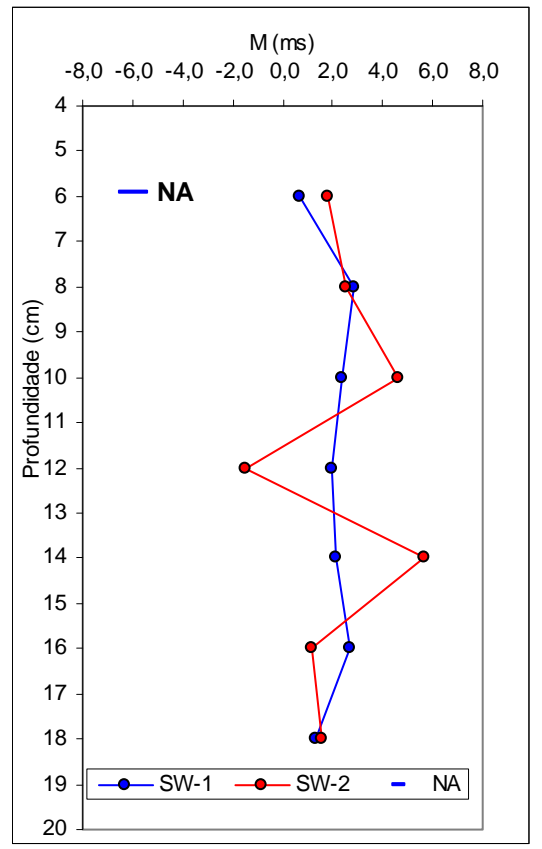

Figura 03 - Curvas de cargabilidade - ensaio de referência (background)

Os resultados relativos às 52 horas após a contaminação apresentam valores próximos aos verificados após 12horas de monitoramento, atingindo um pico de cargabilidades altas (9ms) para a faixa insaturada e se estabilizando em valores próximos a $3 \mathrm{~ms}$ para os sedimentos saturados.

As curvas de cargabilidades da fase final do monitoramento (após 342 horas) revelam variações relativamente aleatórias em seus valores. Entretanto, os valores médios apresentam relativa constância e as cargabilidades associadas à sonda S-02 normalmente revelam valores superiores aos verificados na sonda S01.

Após 1158 horas da contaminação as curvas de cargabilidades apontam valores próximos de 2,5ms para a faixa insaturada dos sedimentos. Com o aumento das profundidades esses valores apresentaram variações pequenas. A faixa saturada dos sedimentos revela cargabilidades que oscilam em torno de $3,0 \mathrm{~ms}$.

Os valores de cargabilidades obtidos após 2406 horas da presença do etanol apontam 2,0ms para a faixa insaturada dos sedimentos. Com o aumento das profundidades esses valores apresentam pequenas variações, atingindo valores médios de $0,5 \mathrm{~ms}$ para a faixa saturada dos sedimentos. 
A cargabilidade aumenta nas faixas insaturadas dos sedimentos nesta fase, e mostraram uma relativa estabilização em torno dos 3ms abaixo do NA.

\section{Discussão e Conclusões}

Foi possível o estabelecer uma relação temporal entre variações no parâmetro físico cargabilidade e o comportamento geoquímico do álcool combustível no ambiente geológico, sob condições atmosféricas.

Este parâmetro físico demonstra ser susceptível a alterações composicionais em fluidos de saturação no ambiente geológico, bem como eventuais modificações, como solubilização, precipitação e decomposição de compostos ou elementos em solução, conforme demonstrado neste e em diversos trabalhos de aplicação da Polarização Induzida em áreas contaminadas.

As profundidades investigadas, em ordem crescente dos níveis foram 2,6cm (Ni01), 7,7cm (NiO2), 13,1cm (Ns01) e 19,0cm (Ns02). Os valores dos níveis d'água dos ensaios realizados foram registrados por meio dos poços P-01 e P-02, e seus valores indicam um valor médio de $10,0 \mathrm{~cm}$ para as perfilagens elétricas.

As curvas de integração de cargabilidades para os dois estratos geoelétricos apresentam oscilações durante todo o monitoramento. Entretanto, em torno de 198 horas essas variações assumem grande amplitude (Figura 6.9).

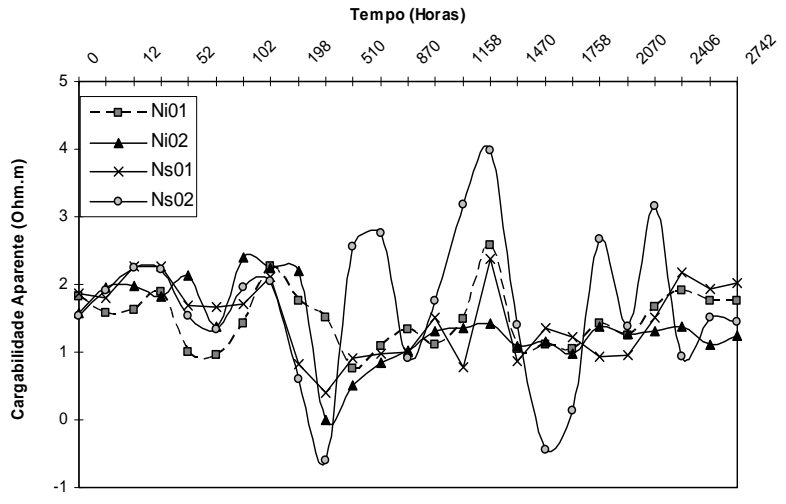

Figura 04 - Curvas integradas de cargabilidades

As oscilações do padrão de variação de cargabilidade foi maior para o último nível do estrato saturado $(19 \mathrm{~cm})$, sugerindo distorções mais bruscas nas regiões próximas ao fundo do tanque.

Os padrões de variações no parâmetro cargabilidade apresentam inconstâncias aparentemente desvinculadas ao período da contaminação. Entretanto, é notório que as maiores amplitudes de variação desse parâmetro estão associadas à níveis com a presença de água, sugerindo a influencia da solução formada no estrato saturado dos sedimentos para as cargabilidades medidas no monitoramento.

As cargabilidades atingem valores mínimos em 198 horas de monitoramento. Esta tendência pode estar associada à influência de fatores externos, como entrada de água de chuva no tanque de monitoramento.
A entrada de $\mathrm{O}_{2}$ no sistema pode estar associada à valores baixos de cargabilidade, em função da maior dissolução de sais, resultando em menor polarização eletrolítica.

\section{Agradecimentos}

Este trabalho contou com o apoio da Coordenadoria de Aperfeiçoamento Pessoal de Nível Superior - CAPES, sob a forma de bolsa, e Fundação de Amparo à Pesquisa do Estado de São Paulo - FAPESP.

\section{Referências}

APPARAO, A.; SIVARAMA SASTRY, S.R. \& SUBRAHMANYA SARMA, V. Depth of detection of buried resistive targets with some electrode arrays in electrical prospecting. Geophysical Prospecting, v.45, p. 365375, 1997.

APPARAO, A.; GANGADHARA RAO, T.; SIVARAMA SASTRY, S.R. \& SUBRAHMANYA SARMA, V. Depth of detection of buried conductive targets with different electrode arrays in resistivity prospecting. Geophysical Prospecting, v.40, p. 749-760, 1992.

ATEKWANA, E.A.; SAUCK, W.A.; WERKEMA JR, D.D. Investigations of geoelectrical signature at a hydrocarbon contaminated site. Journal of Applied Geophysics, $n^{\circ} 44$, p. 167-180, 2000.

ATEKWANA, E.A.; WERKEMA JR., D.D.; ALLEN, J.P., SMART, L.A.; DURIS, J.W.; CASSYDI, D.P.; SAUCK, W.A.; ROSSBACK, S. Evidence for microbial enhanced electrical conductivity in hydrocarbon - contaminated sediments. Geophysical Research Letters, v.31, p. 1-4, 2004.

BELLER, H. R.; GRBIC-GALIC, D; REINHARD, M. Microbial degradation of toluene under sulfate-reducing conditons and influence of iron on the processes. Applied and Environmental Microbiology, vol. 58, no3, p.786-793, 1992.

BRAGA, A. C. O.; MOREIRA, C. A.; CARDINALLI, M. T. Variação temporal da resistividade elétrica em contaminação por gasolina. Geociências, vol. 27, no4, p.517-525, 2008.

CASSIDY, D. P.; WERKEMA, D. D. JR.; SAUCK, W.; ATEKWANA, E.; ROSSBACH, S.; DURIS, J. The Effects of LNAPL Biodegradation Products on Electrical Conductivity Measurements. Journal of Environmental \& Engineering Geophysics, v. 6, nº 1, pg 47-52, 2001.

DRASKOVITS, P.; HOBOT, J.; VERO, L.; SMITH, B. Induced-polarization surveys applied to evaluation of groundwater resources. Society of Exploration Geophysicists, p. 379-396, 1990. 
FERREIRA, M.F.; OLIVEIRA, E.; DUARTE, U. Comportamento da gasolina com etanol (E-20) e da gasolina pura após a simulação de um vazamento em colunas de laboratório. Revista do Instituto de Geociências-USP, v. 4, n.2, p. 91-102, 2004.

FERREIRA, J. \& ZUQUETTE, L.V. Considerações sobre as interações entre contaminantes constituídos de hidrocarbonetos e os componentes do meio físico. Geociências, nº 17, p. 527 - 557, 1998.

GRADY, C. P. L.; DAIGGER, G. T.; LIM, H. Biological wastewater treatment. Marcel Dekker, New York, 2oed., 1999, 1096p.

GRBIC-GALIC, D. \& VOGEL, T. M. Transformation of Toluene and Benzene by Mixed Methanogenic Cultures. Applied and Environmental Microbiology: American Society for Microbiology, vol 53, nº 2, p. 254 - 260, 1987.
MOREIRA, C. A. \& BRAGA, A. C. O. Aplicação de métodos geofísicos no monitoramento de área contaminada sob Atenuação Natural. Revista de Engenharia Sanitária e Ambiental, vol. 14, no2, p.257264, 2009.

ORELLANA, E. Prospeccion Geoelectrica en Corriente Continua, Biblioteca Técnica Philips, Madrid: Paraninfo, 523 p, 1972. 